\title{
Influence of Parenting Styles toward Achievement of Theory of Mind in the Late Childhood
}

\author{
Istiqomah Aminin \\ SDN Dinoyo 1 Malang \\ PGRI \\ Malang, Indonesia \\ isti.aminin@gmail.com
}

\begin{abstract}
The ability to understand the intention, beliefs, wishes or motives of others (theory of mind) is very important to be developed for the children. Caregiving is possible to contribute to the achievement of the theory of mind in children. The aims of this study are to examine the parenting influence on the achievement of the theory of mind and differences in authoritative, authoritarian and permissive parenting towards the achievement of the theory of mind in the last childhood period. The total of the students in this elementary school is 150 students in grade IV - V was involved in this study. The instrument used in this study is the PAQ (Parental Authority Questionnaire) to determine the tendency of parents' parenting and higher order tasks to determine the level of the ToM. The results showed that there was a difference in the level of theory of mind performance in terms of parenting.
\end{abstract}

Keywords- parenting, authoritative, authoritarian, permissive, the theory of mind

\section{INTRODUCTION}

Theory of mind is a mental condition that is very important to be developed in childhood. The existence of the theory of mind will direct children to act appropriately in a social environment. Children begin to develop the theory of mind at a very early age, and these abilities become increasingly elevated during the developmental stage. The achievement of the development of the theory of mind is significantly influenced by parenting [1]. Especially for parents who always provide support and teach their children about social interaction. Harrison's study shows that there is a positive correlation between parenting styles and theory of mind, especially the authoritative parenting style [2].

Acquisition of theory of mind in childhood is influenced by the family environment. The family environment includes parenting and patterns of family interaction [3]. Parents who always revile and express harsh words to their children, the theory of mind of their children also develop negatively. Likewise, with parents who support social conformity, the theory of mind of children will also develop.

In line with the results of Cain's research, Hughes [4] also examined the relationship between parental parenting with the ability of the theory of mind of children. The results of the study showed that the rude parental parenting to their children, contributing to the development of children's theory of mind in a negative direction. For example, parents who often yell, say harshly or beat their children, the child's theory of mind also develops in a negative direction.

Unlike the research on the comparison of parenting in Korea American and Anglo American and its influence on understanding the theory of mind of preschoolers [5]. The results showed that the parenting style of Korea American mothers tends to be authoritarian. The implication for the development of his son's theory of mind is that at the age of 5 years, these Korea American children actually show better performance in theory of mind tasks compared to Anglo American children of their age. In contrast to Anglo American children, with this authoritarian parenting style, the performance of their theory of mind does not develop.

This shows that achieving the theory of mind at each stage of development can be achieved by all different cultures. What is meant by "good parenting" depends on attitudes and behavior that can only be understood by local social culture? All styles of parenting can contribute to the achievement of the theory of mind in children. This is what prompted researchers to examine how parents' parenting influences the attainment of the theory of mind during their final childhood and whether there are differences in authoritative, authoritarian and permissive parenting towards achieving the theory of mind in the late childhood. Knowing this is expected to provide a clearer and broader understanding for practitioners of developmental psychologists or parents in developing children's theory of mind.

\section{THEORY OF MIND}

\section{A. Parenting}

Parenting style is a behavior pattern applied by parents to children and it is relatively consistent over time [6]. This pattern depends on the behavior and attitudes carried out by parents to children, so that the impact can be felt by children, in terms of both negative and positive.

There are three styles of parenting for their children: authoritative, authoritarian and permissive which are used to socialize with children based on the high level of nurturing, maturity demands, communication and control of children's behavior [7]. Each parenting model shows natural differences that emerge from the values taught, parental treatment, behavior, responsiveness, and demands [8].

Authoritative parenting is indicated by the attitude of parents who control and demand but with a warm attitude, there is a two-way communication between parents and children that is done rationally. Parents provide child supervision and strong control and positive encouragement. Children who are cared for authoritatively tend to be active, take initiative, are not afraid of failure, spontaneously because children are given the opportunity to discuss and make decisions in the family. Children who are cared for 
with authoritative parenting will be socially competent, happy, competent, confident and socially responsible [9].

Authoritarian parenting is shown by the attitude of parents who always demand adherence to children, dictate, relationships with children less warm, rigid and hard. Children lack the trust of their parents, children are often punished, and if successful or outstanding children are rarely given praise and prizes. This parenting will produce children with passive behavior and tend to withdraw. Parents' tough attitude will hamper children's initiative. Children who are educated in authoritarian patterns tend to be more aggressive.

Permissive parenting provides little demand and little discipline. Parents do not demand that children be responsible for domestic matters, the child's wishes and attitudes and behavior are always accepted and approved by parents. Children are not trained to comply with applicable regulations and assume that parents are not an active and responsible figure. Because parents are completely free and allow everything, without demanding children. Children who are taken care of permissively have a tendency to be less achievement-oriented, selfish, like to force their desires, low independence, and less responsible. Children will also behave aggressively and antisocially, because from the beginning they were not taught to obey social rules, were never given a penalty when violating the rules set by parents. For children, the presence of parents is a source for achieving children's desires.

From the three explanations of parenting, it can be explained that the difference between authoritative and authoritarian parenting lies in the aspect of psychological control. Psychological control is an effort made by parents so that it can affect psychological and emotional development [10].

\section{B. Theory of Mind}

Theory of mind is the ability to attribute mental conditions such as beliefs, goals, desires, pretenses, knowledge, and others to themselves or others and understand that other people have beliefs, goals, and wills that are different from each other [11].

The term theory of mind leads to the concept of developing children's mental activity. Theory referred to here is a set of frameworks for gathering facts and making predictions [12]. The achievement of the theory of mind is characterized by the ability to be able to recognize various forms of mind, such as dreams, memories, imagination, beliefs. In addition, the achievement of the theory of mind is also shown by the ability to be able to explain causes due to other people's behavior, for example why someone behaves like that. Theory of mind is the ability to understand the thoughts, beliefs, perspectives of others that can affect their behavior [13].

Basically, the theory of mind is very important to be developed, especially in childhood. Theory of mind can be useful for (1) as an initial cue to be able to interact with others appropriately, (2) explain and predict the behavior of others in social interaction, (3) explain events that can be observed (behavior) through events that can be observed (will, desire, etc.), and (4) enhances social-cognitive abilities such as collaboration or metacognition.

\section{Theory of Mind Development Process}

\section{1) Belief-desire psychology}

Theory of mind begins to develop in a complex way starting from the beginning of childhood. Children begin to develop the theory of mind when they can recognize the most basic mental conditions of "desire" [14]. This ability starts to appear around the age of 9 months, and the form is the desire to follow the attention that interests him or joint attention [15].

\section{2) Belief}

After the child can master belief desire, then it will progress to the next stage about the ability to reflect the process of representation and understanding that belief is a form of reality, but not reality itself. Unlike desire, a belief can be right or wrong. The false belief is the understanding that other people have different beliefs with self-confidence.

To determine the ability of false beliefs, false belief tasks are used. In the false belief, the child will be given a series of questions specifically designed to predict whether the child can distinguish between new knowledge stimuli and previous thoughts [16].

Basically, the achievement of false belief does not just appear, but there are several stages in its development. The earliest stages are: (a) first-order false belief. First order false belief is the ability to understand that other people can have different thoughts in the same situation. Named first order, because it only involves one mental state, (b) second-order false belief, if on first order only involves one person's mental condition, then this second order adds another person's mental condition to the person who is thinking about that person, (c) higher order false belief [17].

\section{Factors Affecting the Development of Theory of Mind}

Some experts state that the factors of maturity or maturation are determinants of development. There is a relationship between age and the achievement of the theory of mind [18]. For example, related to the development of false belief, in children aged 5 years, they will not experience difficulties in working on false belief tasks.

In preschool children who often do activities together with their siblings can show good performance in false belief tasks compared to children who do not have siblings. This is because they will gain experience and opportunities to learn about other people's thoughts. And having older siblings or older siblings will also further enhance the development of the theory of mind [19].

Basically, the development of language is also a potential source for developing the theory of mind. Some studies show a correlation between language skills and the development of the theory of mind. The study was not only carried out in normal children but also in autistic children and deaf-mute children.

\section{E. Parental Parenting Effect in Achieving Theory of Mind}

Various forms of relationships have been established throughout the lifespan and the most important is the relationship between parents and children. Every parent wants his children to grow into socially mature individuals. But sometimes, many parents are frustrated to find a good way to make a good child. 
Along with the development of issues about parenting, Diana Baumrind emerged which gave a new paradigm in parenting theory. He argued that parents should not punish or isolate them but they must develop rules for children and devote affection to them. Baumrind broadly divides parenting patterns based on children's social behavior. Parenting patterns are authoritative, authoritarian, and permissive.

Authoritative parenting style or better known as democratic parenting is a parenting pattern for children that gives freedom to children to create and explore various things in accordance with the child's ability to limit censorship and good supervision from parents. Parents' attitudes are also shown by controlling and demanding to children but with a warm attitude. In addition, there is a twoway communication between parents and children that is done rationally. Likewise in determining a rule, parents explain and give reasons to the child by directly dialogue why the rules need to be done or prohibited. So that children can learn to understand the reasons for the rules that their parents have set. This causes children to practice to understand the will, belief or motives of others through their parents so that the ability of the theory of mind can be achieved.

Related to emotional development in these last childhood period, there is a situation called emotional dissemblance. Emotional dissemblance is the child responds to emotions in different ways according to the inner self. For example, a child is given a gift. The prize is actually not attracted to him and not the prize he dreamed of. In children cared for by authoritative parents, he will be taught how to thank people for giving. In addition, children are taught how he must respect the gifts of people. So, if the child refuses a gift, then the child can think that the person who gave the gift will be disappointed. Or the child thinks that the person who gave the gift will consider the child rude and ungrateful for refusing the gift. In this case, the child has the ability to be able to attribute the mind, will, intentions of others so that he can behave according to the rules that already exist.

Authoritarian parenting is a parenting pattern that is shown by the attitude of parents who always demand adherence to children, dictate, relationships with children less warm, stiff and hard. Children lack the trust of their parents, are often punished, and if successful or outstanding children are rarely given praise and prizes.

Authoritarian parenting is shown by parenting in making various rules that are absolute and cannot be contested. The rules must be obeyed by the child, without wanting to pay attention to the child's feelings. Parents will be emotional and angry if children do things that are not in accordance with the things they want. Parents do not give children the opportunity to dialogue about the reasons for a rule to be set and the rules. Thus, children do not have the opportunity to learn to know the intentions, motives or beliefs of others. This causes the development of the theory of mind to be not optimal.

Permissive parenting is a parenting style that gives little demand and is a little disciplined. Parents do not require children to be responsible for household affairs, desires, and attitudes. Child behavior is always accepted and approved by parents. Children are not trained to obey the rules that apply because parents are free and allow everything without demanding the child. This causes the child to have no clear direction about the intentions, beliefs or motives of others. The implication for achieving the theory of mind of a child is to develop or become obstructed.

With regard to permissive parenting, a child is not taught by his parents to obey existing rules so that the child becomes indifferent and unconcerned with the surrounding environment. Likewise in expressing emotions, the child will be arbitrary even emotional expressions that are shown also do not care about the social environment. In relation with the theory of mind, the child who is cared for by this permissive parenting, the ability to read thoughts, intentions, beliefs of others in him that he does not care about or ignore. This is because children are accustomed to not caring about the environment. In this case, it can be said that the theory of mind that should be used as a cue to behave in accordance with social rules does not function optimally.

The rationale of this research begins with the existence of various types of parenting patterns that will affect the achievement of children's theory of mind. Among authoritative, authoritarian and permissive parenting will have its own implications for the achievement of the theory of mind.

\section{METHOD}

\section{A. Research Design}

The design used in this study is a comparative causal research which aims to know the effect of parenting on the achievement of the theory of mind in lastly childhood period and differences in authoritative, authoritarian and permissive parenting towards the achievement of the theory of mind in the late childhood period.

\section{B. Research Subject}

The research was carried out by taking the research subject of students in grade 3 - 5 of State Elementary School of Dinoyo Malang academic year 2016/2017, aged 8-13 years $(\mathrm{M}=10$ and $\mathrm{SD}=0.82)$. The number of subjects in this study was 150 students consisting of 91 female students and 59 students. Another procedure for determining research subjects is that subjects must live and be cared for by their biological parents. The research data collection was conducted in May - June 2017.

\section{Research Instruments}

The scale of parenting used was derived from the adaptation of the Parental Authority Questionnaire (PAQ) developed by Buri (1991). PAQ is used by researchers to measure parenting trends. The Higher Order ToM Task was developed by Stiller \& Dunbar. Higher Order ToM Task is a set of tools used to measure theory of mind. In this measurement, 5 stories are provided that are suitable for the condition of students. This is intended that students can understand various characteristics of each different story. All stories are read by students themselves. Previously the researchers also made sure that all students could read, this was done to avoid the bias of students' inability to read.

Students are given assignments by answering questions by selecting the answers available after reading the story. Students are only allowed one answer that is considered the most correct. Each story is connected with 4 answer choices. 
TABLE II. COMPARISON OF PARENTING RESUlt

The composition is 2 answers related to ToM and 2 answers related to memory. Questions about the theory of mind range from level 0 to level 4 . Level 0 questions include wishes or desires. Level 1 includes belief. Level 2 includes the secondorder theory of mind. While level 3 and 4 are additional levels to test the highest achievement of research subjects.

Each story is given 2 statements about the theory of mind and 2 statements about memory. It is intended to test student concentration and avoid boredom. So, there are 2 questions for each level. The score ranges from 0 to 10 . The conversion of the score of the subject's answer to the ToM level can be seen in table 1 .

\section{Data Analysis}

Data analysis in this study includes the analysis prerequisite test and research hypothesis test. The analysis prerequisite test is needed to find out whether data analysis for testing hypotheses can be continued or not. The analysis prerequisite test carried out in this study includes two parts, namely the sample normality test and the data homogeneity test. (a) Sample Normality Test, this test is intended to determine whether a sample is normal or not (Zuriah, 2006). The technique used to test the sample normality is Kolmogorov-Smirnov, (b) Data homogeneity Test, which is intended to show that two or more groups of sample data come from populations that have the same variance.

\section{RESULT AND DISCUSSION}

\section{A. Result}

Classification of parenting based on the results of the subject's response can be seen that out of 150 research subjects, there were 75 people who had authoritative parenting or about $50 \%$. The score of authoritative parenting has a range of $17-45$ with $\mathrm{M}=33.89$ and $\mathrm{SD}=7.44$. Subjects who have parents with an authoritarian parenting tendency are 49 people or $33 \%$. Authoritarian parenting scores have a range of $10-48$ with $\mathrm{M}=28.28$ and $\mathrm{SD}=$ 9.98. The number of subjects cared for by permissive parenting is 26 people or $17 \%$. The score of permissive parenting has a range of $14-43$ with $\mathrm{M}=28.53$ and $\mathrm{SD}=$ 6.27. The full description is displayed in table 1 .

TABLE I. PARENTING INFLUENCE

\begin{tabular}{|c|c|c|c|c|c|}
\hline Parenting & Frequency & $\begin{array}{c}\text { Percentage } \\
\text { \% }\end{array}$ & $\begin{array}{c}\text { Score } \\
\text { range }\end{array}$ & M & SD \\
\hline Authoritative & 75 & 50 & $17-45$ & 33,89 & 7,44 \\
\hline Authoritarian & 49 & 33 & $10-48$ & 28,28 & 9,98 \\
\hline Permissive & 26 & 17 & $14-43$ & 28,53 & 6,27 \\
\hline
\end{tabular}

Based on the parenting influence on the achievement of the theory of mind, it can be seen that 75 subjects who were cared for by authoritative parenting, which had the highest performance of the theory of mind achievement in the ToM in level 3, as many as 49 subjects. In subjects who were cared for by authoritarian parenting, the performance of the ToM achievement was almost evenly distributed at all levels except the ToM in level 0 . At ToM in level 1 there are 14 students, ToM in level 2 there are 13 students, ToM in level 3 there are 10 students and ToM in level 4 there are 11 students with $\mathrm{N}=46$. While the subjects who are cared for with permissive parenting, the highest performance are shown in ToM in level 2 as many as 14 students with $\mathrm{N}=26$.

\begin{tabular}{|l|c|c|c|}
\hline \multicolumn{1}{|c|}{ Variable } & $\mathbf{1}$ & $\mathbf{2}$ & $\mathbf{3}$ \\
\hline 1. Authoritative parenting & - & $0,64^{*}$ & $0,88^{*}$ \\
2. Authoritarian parenting & $-0,64^{*}$ & - & 0,24 \\
3. Permissive parenting & $-0,88^{*}$ & $-0,24$ & - \\
\hline
\end{tabular}

Based on the answers of subjects according to the ToM level, it can be seen that at the age of 8 there was 1 student who scored 8 , at the age of 9 there were 18 students who scored $\geqslant 8$, at the age of 10 there were 41 students who got $\geqslant 8$, at age 11 years there were 17 students who scored $\geqslant 8$, at the age of 12 there was 1 person who scored $=8$ and at the age of 13 there was 1 person who scored $=8$.

TABLE III. STATISTIC RESUlt

\begin{tabular}{|c|c|c|c|c|}
\hline ToM & Df & Mean Square & F & Sig. \\
\hline Between & 2 & 10.200 & 4.364 & .014 \\
Groups & 147 & 2.337 & & \\
Within groups & 149 & & & \\
Total & & & & \\
\hline
\end{tabular}

Based on the comparison between parenting, it can be seen that there are significant differences in the level of performance of the theory of mind between subjects cared for with authoritative parenting with authoritarian parenting or authoritative parenting, although there is no significant difference in the level of perfection of theory of mind between subjects cared for with permissive parenting with authoritarian parenting.

\section{B. Discussion}

The results showed that there was a difference in the theory of mind performance level in terms of parenting $(\mathrm{F}=$ $4.364, \mathrm{p}=0.014<0.05)$. Subjects who were cared for in an authoritative manner had the higher theory of mind performance compared to subjects who were cared for by authoritarian or permissive parenting. This is in line with the research stated by about theory of mind (ToM), executive functioning (EF) and parenting. The results show that there is a positive correlation between parenting styles and theory of mind, specifically the authoritative parenting with $\mathrm{r}=.43, \mathrm{p}$ $=.05$. In addition, the results of this study are supported by research from McElwain \& Volling that the achievement of the theory of mind is significantly influenced by parenting, especially parents who always provide support and teach their children about social interaction [20].

Authoritative parent attitudes are shown by controlling and demanding to children but with a warm attitude. In addition, there is a two-way communication between parents and children that is done rationally. Likewise in setting a rule, authoritative parents will explain and give reasons to the child by having a direct dialogue on why these rules need to be done or prohibited. So that children can learn to understand the reasons for the rules that their parents have set. This causes the child to have the opportunity to understand the will, beliefs or motives of others through their parents. Parents who often talk about belief to their children, can also directly help with language skills. This language ability is not only verbal language but also nonverbal language. Basically, through language, children express what they see, hear and feel. So, with this language ability, 
children can express reasons related to every event that occurs in life.

Authoritative parenting is indicated by warm parental affection for their children. This harmonious interaction will generate confidence in the child. Children will not be awkward or feel inferior when in a crowd. This will increase children's interaction with others. Coming from this interaction, the child will gain experience and opportunities to learn about understanding the thoughts or intentions of others based on the theory of mind.

Authoritative parental attitudes are also shown by controlling and demanding to children but with a warm attitude. Likewise in determining a rule, parents explain and give reasons to the child by directly dialogue why the rules need to be done or prohibited. So that children can learn to understand the reasons for the rules that their parents have set. This causes the child to practice to understand the will, beliefs or motives of others through their parents.

Based on the description above, children who are cared for in an authoritative manner have a high-performance theory of mind due to direct authoritative parenting can affect language skills, increase experience to interact with other people, all of which contribute to the level performance of the theory of mind. Children have the opportunity to understand the will, beliefs or motives of others.

The achievement of the theory of mind in this study is shown by the ability of subjects to answer higher order tasks that consist of level 0 - level 4 appropriately. Subjects whose performance is at level 0 , means that the theory of mind is only limited to understand the wishes or desires of others. Subjects whose performance is at level 1 began to increase their ability to understand the beliefs of others. The belief that is owned by the child can be true or it can be wrong or more often known as a false belief. Level 2 includes the second-order theory of mind, meaning that the child has the ability to understand the beliefs of others that others think (inferences about someone's belief about another belief). While levels 3 and 4 are additional levels to test the highest achievement of belief from research subjects.

In children who are cared for in an authoritative way, the majority of the performance of the theory of mind reaches the ToM in level 3. This shows, the ability to understand the beliefs of others is not limited to one person but more than two people (inferences about someone's beliefs about another belief about another belief). In fact, in general, the developmental peak of the theory of mind in children aged 910 years is at level 2 .

Unlike the subjects who were cared for with authoritarian parenting, the perfection of the theory of mind was evenly distributed at all levels except level 0 , although the majority were at level 1. It can be assumed that the influence of authoritarian parenting on the achievement of ToM is varied, it means the performance of his theory of mind is stagnant or even can improve the performance of theory of mind $(\mathrm{M}=$ 7.12). While the subjects who were cared for in a permissive manner, the majority of the theory of mind perfection was at level 2. This was in accordance with the majority of the development of the theory of mind in general.

Based on the comparison between authoritative, authoritarian or permissive parenting, the parenting influence that is not significant to the performance of theory of mind is permissive parenting with authoritarianism. This is due to authoritarian parenting shown by rigid parenting. Children are not given logical reasons in explaining events that occur in everyday life. Related to display rules, children become very rigid about regulations or even obey regulations. Although sometimes children do not know what reason they must obey the rules. So, children do not have the opportunity to learn to know the intentions, motives or beliefs of others. This can affect the performance of achieving the theory of mind.

Likewise with permissive parenting that gives little demand and a little discipline. Children are not trained to obey the rules that apply because parents are free and allow everything without demanding the child. This causes the child to have no means to learn about the intentions, beliefs or motives of others through parenting taught by his parents. The implication is that the achievement of children's theory of mind is not maximized.

Based on the results of the study, basically from the three parenting styles, namely authoritative, permissive and authoritarian can influence the performance of theory of mind. This is shown from the answers of subjects who were cared for by authoritarian and permissive parenting, some children have achieved the higher-order theory of mind (ToM in level 4). One of the causes is age. This is because subjects who are cared for by authoritarian and permissive ways can achieve higher-order theory of mind levels over the age of 11 years, higher-order theory of mind can be achieved after the age of 6 years, but the majority of normal children began to develop at its peak around the age of 9-10 years.

Based on the level of theory of mind, the majority of subjects have been able to reach ToM in level 1 and 2 which are indicated by the answers of subjects who correctly answer all the questions presented in the story. However, at ToM in level 3 and 4, there is a decrease in the number of correct answers. The performance of ToM in adults is better at level 5 than ToM in level 4 . That is, the development of the theory of mind is more constant in children than adults. This theory of mind will continue to develop during school age. The peak ranges are between the ages of 9-10 years.

\section{CONCLUSION}

This research concluded that there was a difference in the level of theory of mind performance in terms of parenting. Subjects who were cared for in an authoritative manner had the higher theory of mind performance compared to subjects who were cared for by authoritarian or permissive parenting. For the next researchers can do similar research related to gender, age, executive function, intelligence or other variables that can affect the performance of theory of mind.

\section{REFERENCES}

[1] McElwain. N L, and Volling. B L, "Attachment Security And Parental Sensitivity During Infancy: Associations With Friendship Quality And False-Belief Understanding At Age 4". Journal Of Social And Personal Relationships, vol. 21, 2004, pp. 639-667.

[2] Baumrind. D, "The Influence Of Parenting Style On Adolescent Competence And Substance Use". Journal of Early Adolescence. vol. 11(1), 1991, pp. 56-95.

[3] Cain. K, Goubet. N, and Birch. S, "Theory of mind and Family Environment: Developing a Richer Model”, unpublished. 
[4] Kaisa. A Hakan. S, and Jari-Erik. N, "Parenting Styles And Adolescents' Achievement Strategies". Journal of Adolescence, vol. 23(2), 2000, pp. 205-222.

[5] Vinden. G, Penelope, and Frances. L Hiatt, "Parenting Attitudes And Children's Understanding Of Mind: A Comparison Of Korean American And Anglo-American Families". Journal Cognitive Development, vol. 16, 2001, pp. 793-809.

[6] Siegler. S R, and Alibali. W M, “Children's Thinking”. New Jersey: Prentice-Hall, 2005.

[7] Baron-Cohen. S, "Theory of Mind In Normal Development And Autism”. Cambridge: University of Cambridge Press, 2001.

[8] Wellman. H M, Cross. D, and Watson. J, "Meta-Analysis Of TheoryOf-Mind Development: The Truth About False Belief". Journal of Child Development, vol. 72, 2001, pp. 655-684.

[9] Harrison. M R, "Executive Function, Parenting Style, And Theory Of Mind”. Journal of Cognitive Development, 10, 2006, pp. 483-527.

[10] Tomasello. M, "Having Intentions, Understanding Intentions, And Understanding Communicative Intentions". Mahwah NJ: Lawrence Erlbaum, 1999.

[11] Wagner. K V, "Parenting styles: The four styles of parenting", unpublished.

[12] Buri. J, "Parental Authority Questionnaire Revised". Journal of Personality Assessment, vol. 57(1), 1991, pp. 110-119.

[13] Hughes. C, Jaffee. S R, Happe. F, Taylor. A, Caspi. A, and Moffitt. T E, "Origins Of Individual Differences In Theory Of Mind: From
Nature To Nurture". Journal of Child Development, vol. 76, 2005, pp. 356-370.

[14] Symons. D, "Mental State Discourse, Theory Of Mind, And The Internalization Of Self-Other Understanding". Developmental Review, vol. 24, 2004, pp. 159-188.

[15] Bjorklund. F David, "Children's Thinking: Developmental Function And Individual Differences”. Wadsworth: Thomson Learning, 2000.

[16] Cutting. L A, and Dunn. J, "Theory Of Mind, Emotion Understanding, Language, And Family Background: Individual Differences And Interrelations". Journal Child Development, vol. 70, 2003, pp. 853-865.

[17] Dunn. J, Brown. J, Slomkowski. C, Tesla. C, and Youngblade. L, "Young Children's Understanding Of The Other People's Feelings And Beliefs: Individual Differences And Their Antecedents". Child Development, vol. 62, 1991, pp. 1352-1366.

[18] Hughes. C, and Rosie. E, "Positive And Protective: Effects Of Early Theory Of Mind On Problem Behaviors In At-Risk Preschoolers". Journal of Child Psychology and Psychiatry and Allied Disciplines, vol. 48, 2007, pp. 1025-1032.

[19] Premack. D G, and Woodruff. G, "Does The Chimpanzee Have A Theory Of Mind". Behavioral and Brain Sciences, vol. 1, 1978, pp. 515-526.

[20] Ribeiro. L, "Construction And Validation Of A Four Parenting Styles Scale", unpublished. 